\title{
Veranicos no Rio Grande do Sul - Nova metodologia para quantificação de eventos
}

\author{
Veranicos at Rio Grande do Sul - new methodology for quantification of events
}

\author{
Humberto Conrado*1, Glauber Lopes Mariano ${ }^{1}$, Lucas Conceição Carvalho ${ }^{1}$
}

${ }^{1}$ Faculdade de Meteorologia, Universidade Federal de Pelotas, Pelotas, Brasil

\begin{abstract}
Resumo
Apesar da região onde se situa o estado do Rio Grande do Sul possuir estações bem definidas, durante o inverno a região pode apresentar, por alguns dias, padrão anômalo em relação a seus valores de temperatura (máxima e mínima diária) e precipitação (estiagem), sendo conhecido como períodos de veranico. O trabalho apresenta uma nova metodologia, abordando valores climatológicos para caracterizar limiares para determinação de veranicos em cada localidade e, dessa forma, remover influências topográficas ou locais. Utilizaram-se dados de 11 estações meteorológicas operadas pelo INMET, no período de 1961-2011, para determinação dos limiares e identificação de veranicos. Percebe-se que os veranicos apresentam seu máximo em direção a oeste-noroeste do estado com um mínimo na região litorânea e extremo norte do estado. No estudo sinótico da ocorrência de um veranico percebe-se um padrão clássico do tipo bloqueio atuando sobre a região e contribuindo para a ocorrência do veranico.
\end{abstract}

Palavras-chave: veranico, Rio Grande do Sul, Bloqueio, metodologia.

\begin{abstract}
Despite the region where Rio Grande do Sul is located having well defined seasons, during winter the region may show, for some days, anomalous pattern related to the values of temperature (daily maximum and minimum) and precipitation (drought), being known as periods of veranico, portuguese word meaning "little summer". This study shows a new methodology approaching climatological values to describe thresholds for determination of veranicos at each location and, thus, removing local or topographic influences. Data of 11 meteorological stations operated by INMET were used for the period from 1961-2011 to determine the thresholds and identify the veranicos. It can be seen that the veranicos present their maximum towards west-northwest of the state with a minimum at the seaside region and extreme north of the state. At the synoptic study of the veranico occurrence, it can be seen a classic pattern of atmospheric blocking acting over the region and contributing to the occurrence of the veranico.
\end{abstract}

Keywords: veranico, Rio Grande do Sul, block, methodology

*glaubermariano@gmail.com

Recebido: 13/03/2014 Aceito: 13/03/2014 


\section{Introdução}

A região compreendida pelo estado do Rio Grande do Sul situa-se no cinturão de latitudes subtropicais, cujo clima apresenta as estações do ano bem definidas, sendo o mês de julho o período regularmente mais frio e típico do inverno. O clima da região apresenta um regime de chuvas uniforme ao longo do ano, sendo determinado basicamente pela passagem regular dos sistemas frontais. Entretanto, entre os meses de maio e setembro, os sistemas meteorológicos sinóticos de latitudes médias atuam na região com maior frequência e intensidade, influenciando mais o regime de chuvas e ocasionando a queda nas temperaturas, com a consequente redução de dias sob a presença de massas de ar quente oriundas das latitudes baixas. Estas condições sazonais também são caracterizadas por uma intensificação da circulação atmosférica em níveis médios e superiores da troposfera, o que proporciona a condição mais transiente dos sistemas migratórios.

Por tratar-se de uma zona de transição aos climas das latitudes médias, o regime do tempo na região apresenta ocasionalmente a interrupção regular da invasão de massas frias oriundas de latitudes mais ao sul, situação na qual a região fica sob condições de anomalia quente e seca. Segundo Satyamurty et al (1998), normalmente, estas situações estão associadas à ação de sistemas de bloqueio na circulação atmosférica sobre a América do Sul, que ocasionam o desvio da circulação atmosférica, com a consequente interrupção do deslocamento dos sistemas de precipitação sobre a região. Os autores citam que o fenômeno ocorre na América do Sul na região ao sul de aproximadamente $15^{\circ} \mathrm{S}$, a leste dos Andes, no meio ou na última metade do inverno, estando as altas temperaturas relacionadas com subsidência em escala regional sobre a América do Sul tropical e subtropical, a leste de $65^{\circ} \mathrm{W}$, o que inibe o avanço de massas de ar frio para o norte de $30^{\circ} \mathrm{S}$.

A situação de massas de ar quente e seco, estacionadas sobre a região, interrompendo o regime da estação fria do ano e resultando em ausência de precipitações sobre a porção meridional do Brasil, tem sido descrita como veranicos quando persistem por quatro ou mais dias. Neste sentido, o estudo pioneiro caracterizando a ocorrência de veranicos no Rio Grande do Sul foi conduzido por Machado (1950) apud Jacóbsen (1999). Entretanto, o conceito tem sido aplicado a outras regiões e condições climáticas do país. Satyamurty et al (1998) cita que em regiões tropicais do Brasil o termo tem sido aplicado a períodos secos incidentes sobre a estação chuvosa, situação em que a ausência de precipitações também está associada a temperaturas mais elevadas. $\mathrm{O}$ termo também foi usado por Sleiman e Silva (2008) para analisar a incidência de períodos secos no Rio Grande do Sul, entre os meses de outubro e março, sazonalmente mais quente.

Em regiões temperadas e subtropicais, a incidência de veranico sobre o período mais frio do ano é tipicamente indicada pela ocorrência consecutiva de temperaturas muito acima da média para a época do ano e pelos valores de precipitação nula ou insignificante. Entretanto, estes eventos, conforme mencionados por Machado (1950) apud Jacóbsen (1999), também estão associados a condições atmosféricas de baixo índice de circulação e pouca nebulosidade, indicadores que também têm sido usados para caracterizar condições de veranicos. A metodologia utilizada por este autor apresenta como critérios para a identificação da ocorrência de veranicos no Rio Grande do Sul condições atmosféricas apresentando temperatura máxima superior a $25^{\circ} \mathrm{C}$; temperatura mínima superior a $12^{\circ} \mathrm{C}$; céu limpo ou com névooa; calmaria ou ventos fracos (menor ou igual a 5,4 m.s , segundo a escala Beaufort) e duração mínima de quatro dias. Estes critérios tornaram-se a principal referência para compor a metodologia de estudos posteriormente realizados a respeito da ocorrência do evento sobre a região.

Lima (1985) apud Acosta e Carvalho (2004) aplicaram metodologia semelhante à de Machado (1950), mas com variação nos limiares para caracterizar a ocorrência de veranicos na região metropolitana de Porto Alegre, identificando uma incidência maior em maio. Em um estudo mais abrangente sobre a região, Braun et al (2000) aplicaram a metodologia de Machado (1950) em sete localidades do Rio Grande do Sul sobre o período entre maio e agosto, identificando uma incidência máxima de veranicos em maio e mínima em junho e julho, bem como uma maior ocorrência nas regiões norte e oeste do Rio Grande do Sul. Scaglioni e Chapa (2003) apud Acosta e Carvalho (2004) apontam que o período de incidência do fenômeno em Pelotas ocorre desde a segunda quinzena de abril até o final de agosto. Assis et al (2006), baseando-se na metodologia de Machado (1950), analisaram a ocorrência de veranicos entre abril e agosto para a cidade de Pelotas, identificando uma incidência elevada para abril, mas com resultados entre maio e agosto semelhantes aos identificados por Braun et al (2000).

Acosta e Carvalho (2004) utilizaram os critérios da metodologia adotada por Lima (1985) apud Acosta e Carvalho (2004) e analisam a situação sinótica associada ao evento de veranico identificado nas observações de Pelotas no período de 25 a 28 de agosto de 2002. Os autores comprovam os padrões de temperatura elevada e umidade baixa na atmosfera e identificam a atuação de um anticiclone de bloqueio sobre o Oceano Atlântico na latitude próxima ao Rio Grande do Sul.

Os resultados destes estudos comprovaram a incidência de veranicos no Rio Grande do Sul e, também, demonstraram as características típicas das condições atmosféricas durante este fenômeno. Entretanto, a comparação entre os resultados mostram diferenças na incidência dos eventos sobre o Rio Grande do Sul, havendo desigualdade na distribuição sazonal e pouco detalhamento quanto à sua abrangência geográfica. 
Isto pode ser devido a fatores climáticos influenciando localmente o regime climático de cada local de estudo, associado à aplicação de uma metodologia fundamentada em critérios fixos para a identificação de veranicos.

Além dos fatores acima mencionados, existe também a desigualdade no período frio, considerado como sujeito a incidência de veranicos, sendo que alguns estudos consideraram o inicio do período de estudo em abril, enquanto outros consideram em maio, assim como o término é considerado ou até setembro ou até agosto. Climatologicamente para a região, setembro (fim do inverno) é mais frio que abril e equipara-se a maio (meio do outono) e aproximadamente, em parte da região, outubro equipara-se termicamente a abril.

Aplicando uma metodologia diferente, com critérios de identificação baseados nas médias e desvios padrões dos elementos climáticos usados, Luz et al (2012) analisaram a incidência de veranicos na localidade de Passo Fundo no período sazonal que vai de maio a setembro e, assim, identificaram uma incidência máxima em agosto e mínima em julho. A metodologia foi aplicada por Conceição et al (2013) sobre doze localidades no Rio Grande do Sul sobre o mesmo período sazonal, gerando resultados que mostram claramente uma ocorrência máxima do evento no estado em agosto. Os autores também apontam uma ocorrência desigual sobre a região estudada, apresentando uma distribuição de incidências maiores a oeste e noroeste e mínimas ao sul, leste e nordeste do estado.

Os resultados encontrados por Conceição et al (2013) mostram-se mais coerentes, porém as análises são superficiais e carecem em detalhamento com respeito à abrangência geográfica do fenômeno sobre o estado, assim que ainda é necessário um aprofundamento no estudo da incidência de veranicos sobre o Rio Grande do Sul por meio desta metodologia.

Este estudo da ocorrência de veranicos no Rio Grande do Sul compreende uma análise da sua incidência através de séries de observações meteorológicas de superfície no Rio Grande do Sul e da análise sinótica de um evento de veranico que ocorreu sobre a região.

\section{Metodologia}

A análise da incidência de veranicos é feita sobre o período de 1991 a 2011, compreendendo 21 anos de dados. O conjunto de dados utilizados compreende valores diários de temperatura máxima e mínima do ar e precipitação, para o período de 1961 a 2011, totalizando 51 anos de dados, gerados por 11 estações meteorológicas convencionais de superfícies no Rio Grande do Sul (tabela 1), operadas pelo Instituto Nacional de Meteorologia (INMET). O período de 1961 a 1990 (30 anos de dados) é usado como referência para o cálculo dos valores limites que compõem o critério para identificação de eventos de veranico.

A identificação dos eventos de veranicos no Rio Grande do Sul é tomada sobre o período sazonal de maio a setembro, considerado aqui como o segmento frio do ano por considerações subjetivas. $O$ critério para identificação de condições características do evento compreende um período recorrente de, no mínimo, 04 dias consecutivos com precipitação diária inferior a $01 \mathrm{~mm}$, associado com

Tabela 01 - Localização das estações Meteorológicas do INMET utilizadas para identificação de veranicos no estado do Rio Grande do Sul.

\begin{tabular}{|l|c|c|}
\hline Estação meteorológica & Latitude (graus) & Longitude (graus) \\
\hline Bagé & $-31,35$ & $-54,01$ \\
\hline Bom Jesus & $-28,67$ & $-50,53$ \\
\hline Encruzilhada do Sul & $-30,53$ & $-52,52$ \\
\hline Iraí & $-27,18$ & $-53,23$ \\
\hline Passo Fundo & $-28,23$ & $-52,40$ \\
\hline Pelotas & $-31,80$ & $-52,25$ \\
\hline Porto Alegre & $-30,05$ & $-51,17$ \\
\hline Santa Maria & $-29,70$ & $-53,70$ \\
\hline Santa Vitória do Palmar & $-33,52$ & $-53,35$ \\
\hline São Luiz Gonzaga & $-28,42$ & $-54,96$ \\
\hline Torres & $-29,35$ & $-49,73$ \\
\hline Uruguaiana & $-29,84$ & $-57,08$ \\
\hline
\end{tabular}


anomalias de temperaturas máxima e mínima superando valores limites definidos para cada mês do período sazonal de estudo por localidade. Os valores limites de temperatura máxima e temperatura mínima mensal sazonal de cada localidade são determinados pela soma entre as respectivas médias e desvios padrão mensais de cada localidade. O cálculo da normal climatológica mensal e do desvio padrão mensal das respectivas séries de temperatura máxima e mínima diárias, para os meses de maio a setembro, é obtido sobre o período de 1961 a 1990 (30 anos de dados).

A identificação dos veranicos realizou-se entre 1991 e 2011 a partir dos limiares de temperatura máxima e mínima obtida no período de 1961 a 1990 para cada localidade apresentada na tabela 1.

O estudo sinótico é realizado sobre um caso selecionado devido à sua duração e abrangência dentre as localidades analisadas. Para o estudo são analisados campos meteorológicos médios diários e campos meteorológicos de anomalia média diária, obtidos de dados de reanálise do National Centers for Environmental Prediction (NCEP) dos Estados Unidos com resolução espacial de $2,5^{\circ} \times 2,5^{\circ}$. As variáveis meteorológicas utilizadas são: pressão ao nível médio do mar, altura geopotencial, componentes zonal e meridional do vento, temperatura do ar, umidade relativa, água precipitável e velocidade vertical. Os campos foram analisados para os níveis padrões de 1000 a 200 hPa.

\section{Resultados e discussão}

\section{a) Análise da ocorrência de veranicos}

O total de ocorrências contabilizadas em cada localidade (Figura 1) revela um padrão de incidências que cresce significativamente para oeste e noroeste, a partir de incidências mínimas no leste do estado, porém com valores menores ao norte. A cidade de São Luiz Gonzaga, situada no noroeste do estado, é a que apresenta a maior ocorrência, com um total de 34 casos identificados no período de análise. Sobre os 21 anos de análise, o fenômeno foi identificado em 5 a 6 anos nas cidades do litoral e no extremo norte, em torno de 9 a 13 anos em cidades do interior e em 15 anos em São Luiz Gonzaga, no noroeste.

O total de ocorrências contabilizadas com referência ao mês, em cada localidade, está representado de forma gráfica na Figura 2. Os resultados apresentados mostram que, ao longo do período sazonal de estudo, a incidência de veranicos no estado varia pouco de maio a julho, sendo um pouco menor neste último, então, se apresenta máxima em agosto e mínima em setembro. Â exceção de setembro, também é observado um padrão de incidência crescente de leste para oeste nas ocorrências contabilizadas com referência ao mês. Maio apresenta uma graduação crescente de leste para oeste mais espaçada e o evento se mostra mais presente
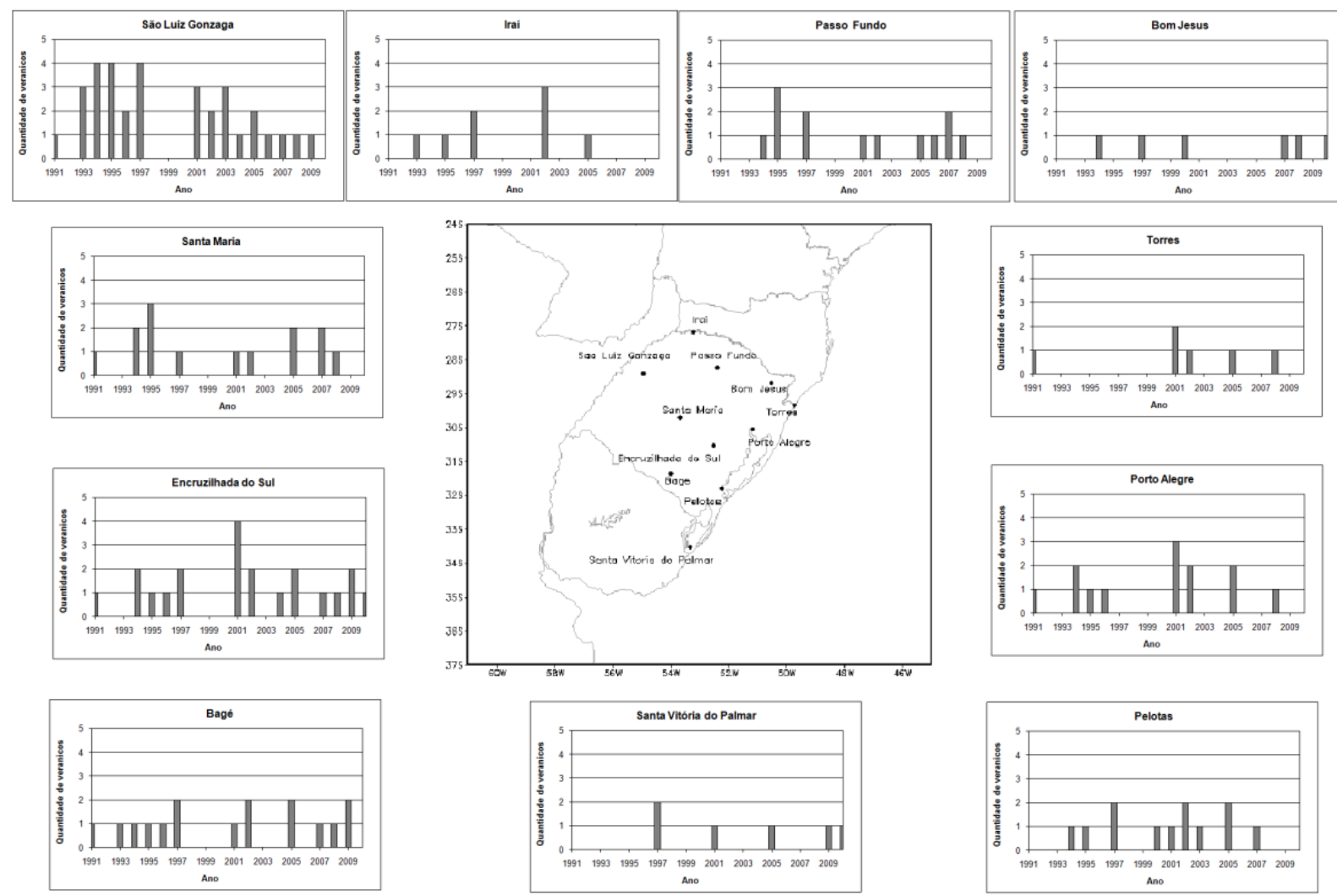

Figura 1 - Quantificação anual de ocorrência de veranicos nas localidades estudadas entre 1991-2011. 

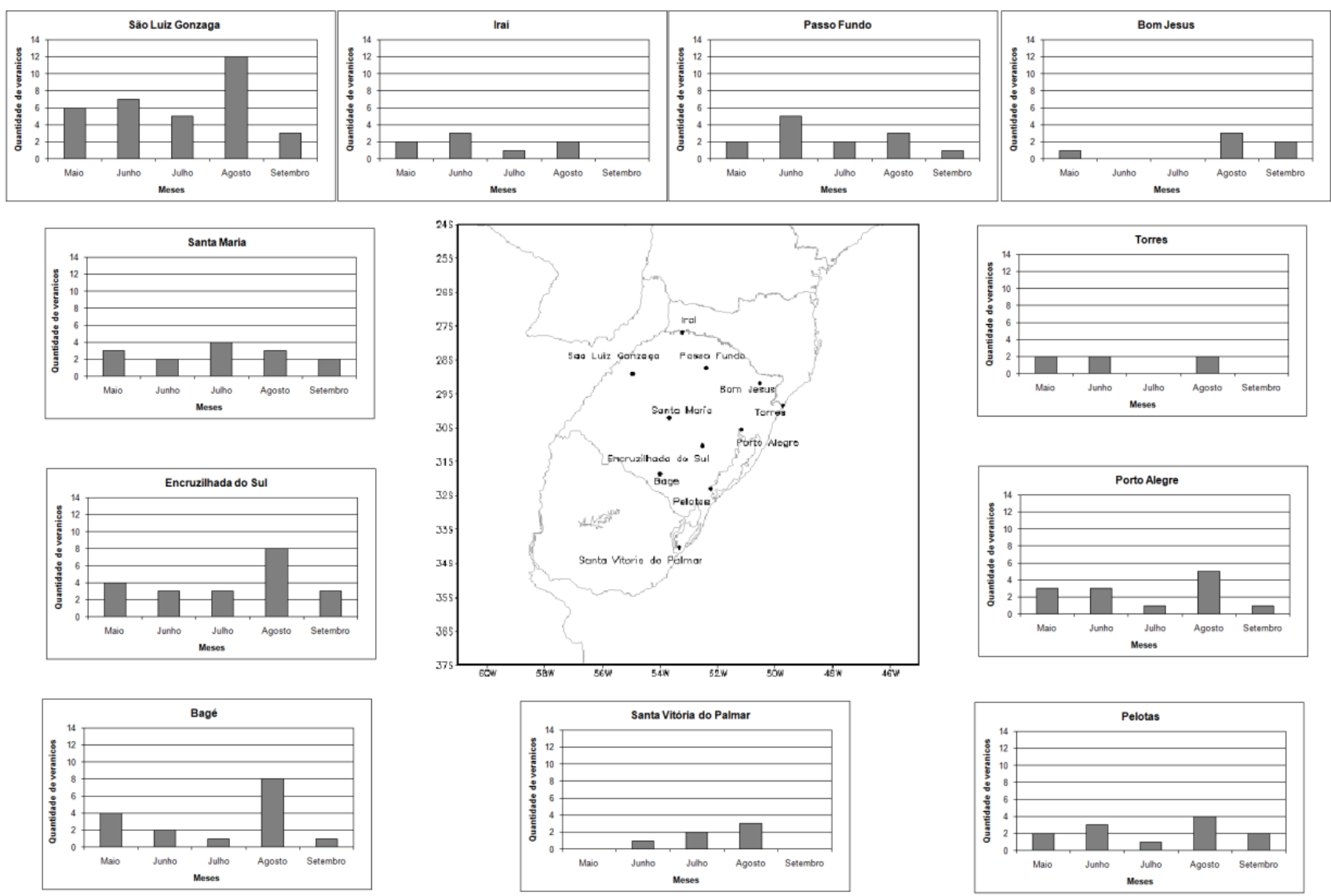

Figura 2 - Quantificação mensal de ocorrência de veranicos nas localidades estudadas entre 1991-2011.

sobre todo o estado, com a maior incidência em São Luiz Gonzaga, com 06 eventos, e no outro extremo, Santa Vitória do Palmar que não registrou ocorrência. Junho e julho apresentam padrão semelhante de distribuição geográfica das ocorrências, com maiores incidências totais concentradas no noroeste. Entretanto, julho apresenta menores valores não só no litoral, mas também ao sul e ao norte, assim que as maiores incidências recuam de forma concentrada a noroeste do estado.

Em Agosto, por ser o mês que apresenta maior ocorrência de veranicos no estado, a incidência de eventos apresenta-se crescendo rápido a partir do litoral, o que confere a este mês a maior amplitude de variação geográfica da incidência local (apenas 02 casos em Torres e 12 casos em São Luiz Gonzaga, no noroeste do estado). Setembro, por ser o mês que apresenta as menores ocorrências, mostra uma menor variação geográfica da incidência local, variando entre ausência de casos no litoral e o máximo de 04 eventos em São Luiz Gonzaga, no noroeste do estado.

Os resultados da Figura 2 apresentam diretamente a variação sazonal na incidência de veranicos localmente. Observa-se nos gráficos que, com exceção de duas localidades no norte do estado, predomina o máximo de ocorrência como sendo no mês de agosto. As cidades de Passo Fundo e Iraí, situadas no norte do estado, apre- sentam maiores incidências no mês de junho. Em geral, sobre o território, a incidência de veranicos é maior em maio e junho e, em contrapartida, é verificada ocorrência mínima (ou ausência) em setembro e julho.

As localidades de Bom Jesus (situada a nordeste) e Torres (situada a nordeste e no litoral), onde as incidências são mínimas, apresentam padrões diferentes. Bom Jesus apresenta ocorrências concentradas no final do inverno (agosto-setembro) e em Torres no inicio do período frio (maio-junho).

\section{b) Análise sinótica de um evento de veranico}

Dentre os eventos de veranico identificados que ocorreram no território do Rio Grande do Sul, entre 1991 e 2011, foi selecionado um caso para análise sinótica das condições atmosféricas, levando em consideração a duração longa do evento e a abrangência sobre o estado. $\mathrm{O}$ evento selecionado ocorreu entre 22 e 31 de agosto de 1995 e foi registrado em sete localidades, apresentando duração variando entre quatro e cinco dias no sul do estado e alcançando nove e dez dias no norte e noroeste, respectivamente.

Durante o período de ocorrência do evento de veranico sobre o território do Rio Grande do Sul, as análises dos campos de altura geopotencial em níveis médios e supe- 
riores revelam a presença de configurações que atuaram como bloqueio no setor da América do Sul. No campo de geopotencial em $500 \mathrm{hPa}$ (Figura 3 - mostrado apenas os dias 24 e 27) é observado entre os dias 22 e 27 de agosto a presença de uma configuração de dipolo (uma crista ao sul e um cavado ao norte) sobre o Oceano Pacífico, a oeste da América do Sul, e de uma crista posicionada sobre o leste da América do Sul. O campo do vetor vento médio diário em $250 \mathrm{hPa}$ (Figura 4 - mostrado apenas os dias 24 e 27) mostra uma bifurcação do escoamento sobre o Oceano Pacífico, associada à configuração de bloqueio observada nos campos de altura geopotencial, com o ramo norte contornado a crista adjacente a leste. Associado a este ramo, é observada a presença da corrente de jato no setor entre o cavado e a crista. O posicionamento da corrente de jato, ao sul e oeste do sul do Brasil, indica que o estado do Rio Grande do Sul está sobre a atuação da atmosfera tropical.

Nos campos de pressão ao N.M.M.(nível médio do mar), média diária 250hPa (Figura 5 - mostrado apenas os dias 24 e 27), é observado entre os dias 22 e 27 de agosto a presença de baixas pressões sobre o norte da Argentina e sul do Paraguai. Durante este período, um anticiclone extratropical migratório, inicialmente posicionado no centro da Argentina, desloca-se para o Oceano Atlântico afastando-se da América do Sul. Sobre o sul do Oceano Pacífico e próximo da América do Sul, abaixo da crista em níveis médios e superiores, há a presença de um anticiclone. O campo de anomalias de pressão ao N.M.M. média diária (Figura 6 - mostrado apenas os dias 24 e 27) mostra que uma anomalia de altas pressões em baixos níveis persistiu neste período sobre o Oceano Pacífico em $95^{\circ} \mathrm{W}$ e $55^{\circ} \mathrm{S}$.

Percebe-se a presença, em baixos níveis da atmosfera, de uma massa de ar muito seca sobre a região central da América do Sul, indicadas por valores abaixo de $50 \%$ de umidade relativa média diária. A magnitude da diminuição da umidade, nos baixos níveis da atmosfera, pode ser avaliada pelo campo de anomalia de umidade relativa média diária (Figura 8 - mostrado apenas os dias 24 e 27). As análises deste campo já revelam a presença, entre os dias 23 e 25, de condição de anomalia negativa
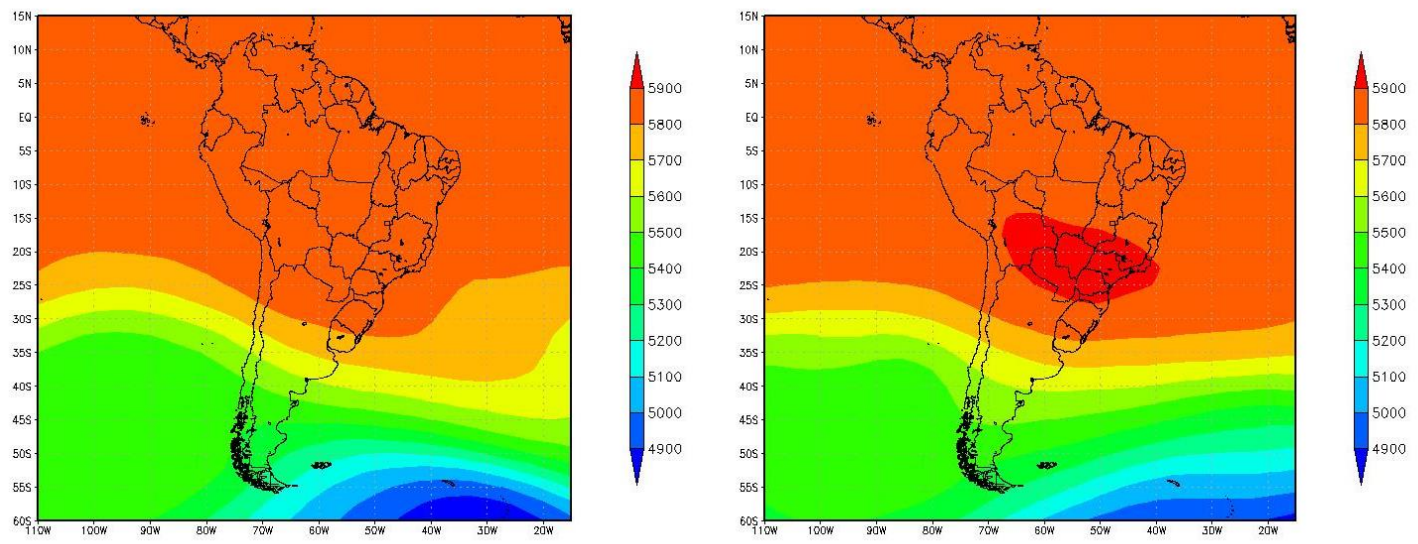

Figura 3 - Altura geopotencial em 500hPa dos dias 24 e 26 de agosto de 1995.
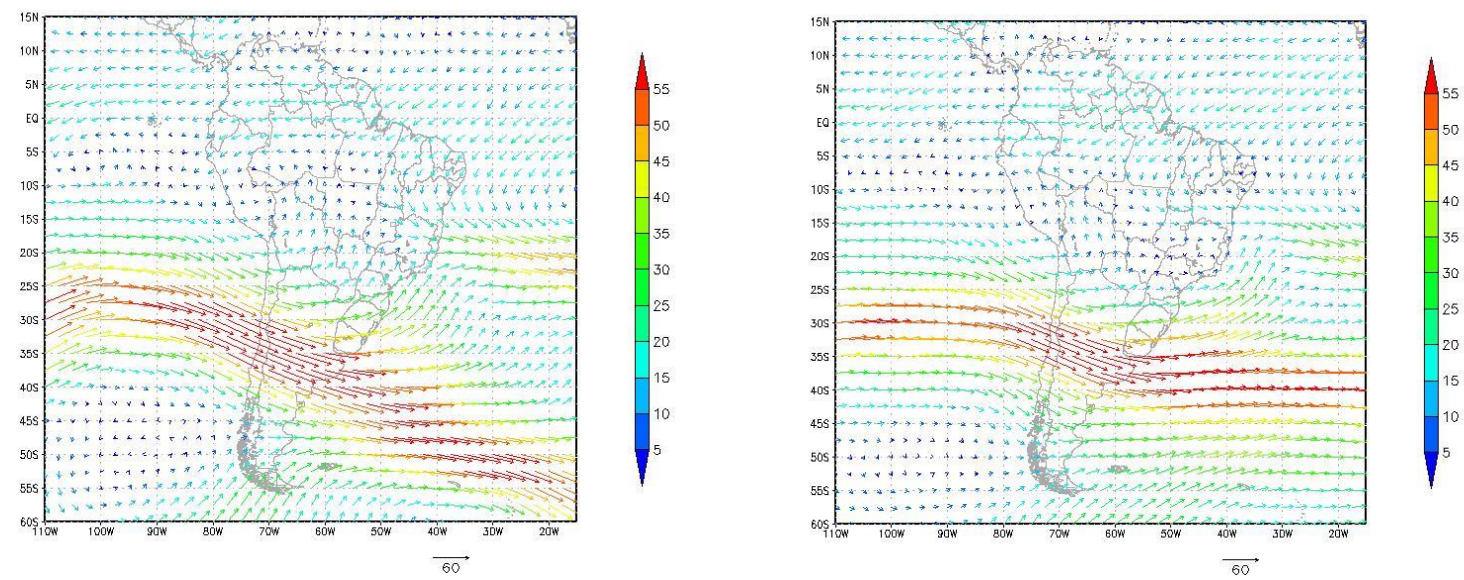

Figura 4 - Vetor vento médio diário em 250hPa dos dias 24 e 26 de agosto de 1995. 

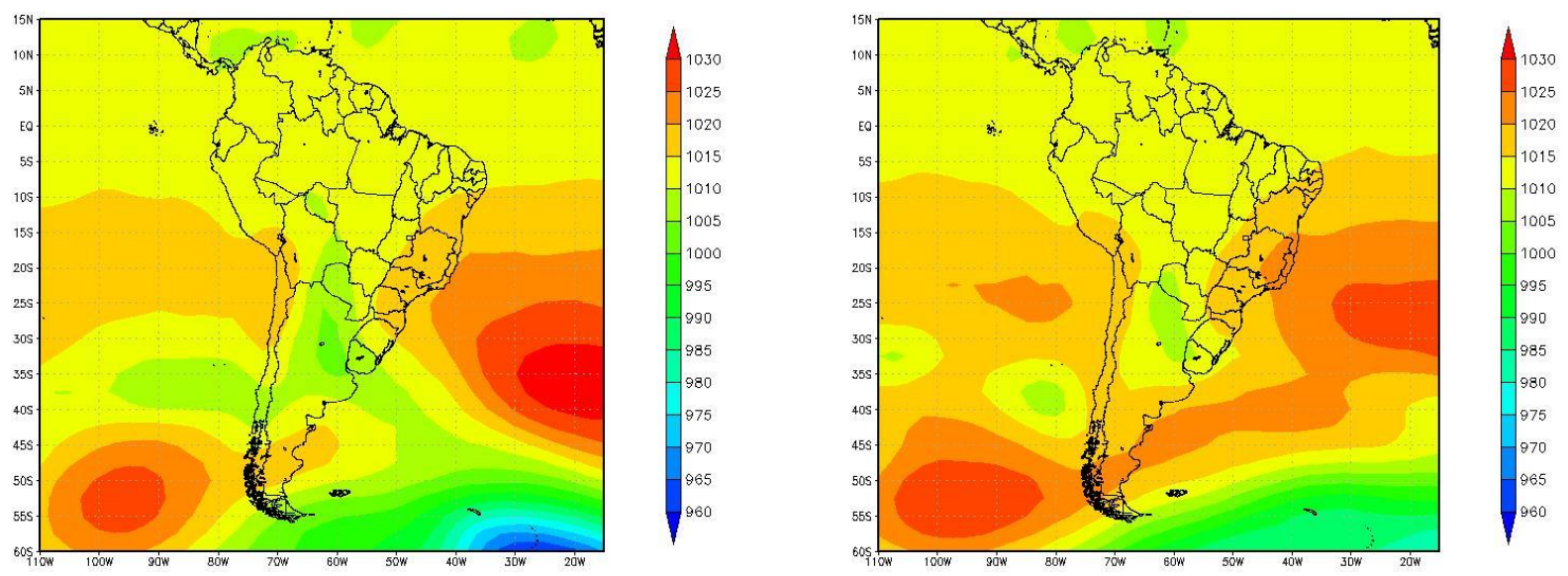

Figura 5 - Pressão ao N.M.M. média diária dos dias 24 e 26 de agosto de 1995.
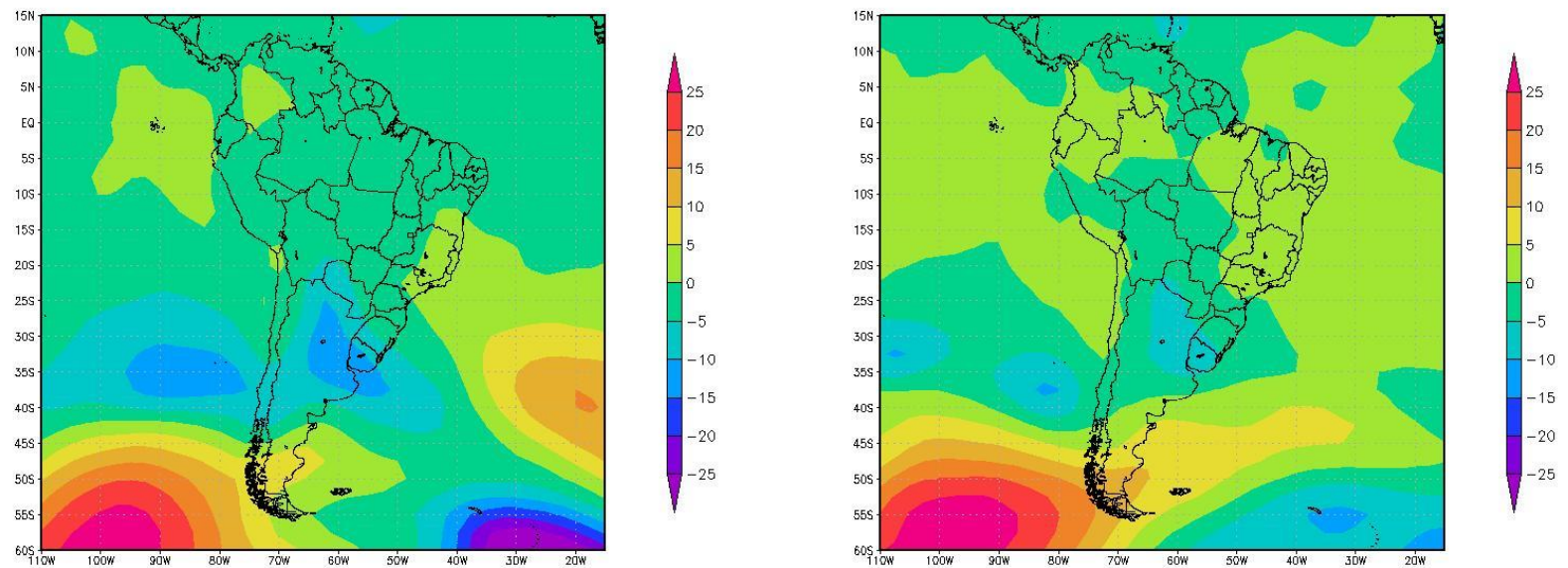

Figura 6 - Anomalias de pressão ao N.M.M. média diária dos dias 24 e 26 de agosto de 1995.
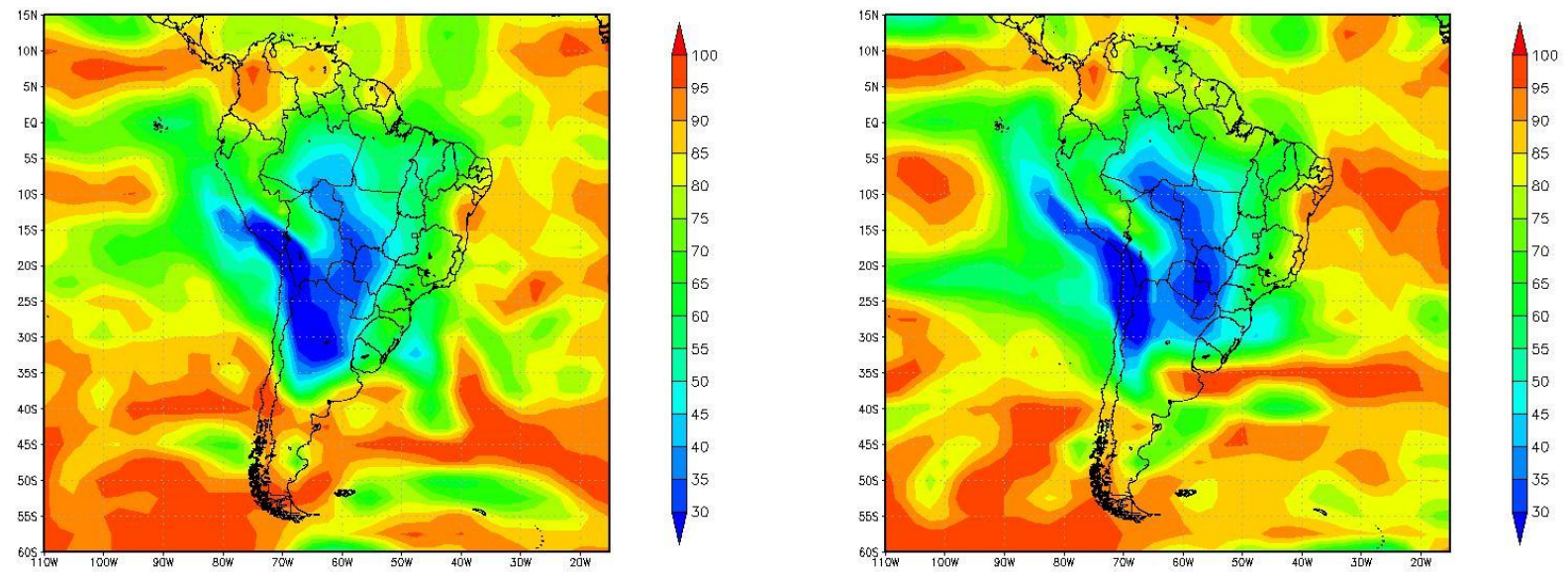

Figura 7 - Umidade relativa média diária em 925hPa dos dia 24 e 26 de agosto de 1995. 
sobre o norte da Argentina e Paraguai e que nos dias 26 e 27 esta anomalia intensifica e se expande por sobre a região sul do Brasil.

As análises de temperaturas médias diárias revelam que, entre os dias 23 e 29 (Figura 9 - mostrado apenas os dias 24 e 27), temperaturas elevadas persistem sobre o centro-norte da Argentina, Paraguai e sobre sul e sudeste do Brasil, com núcleo acima de $30^{\circ} \mathrm{C}$ sobre o norte do Paraguai e sul da Bolívia. Sobre o Rio Grande do Sul as temperaturas médias diárias situam-se acima de $20^{\circ} \mathrm{C}$ e superam $25^{\circ} \mathrm{C}$ no noroeste do estado. No campo de anomalia de temperaturas médias diárias (Figura 10 mostrado apenas os dias 24 e 27), condições de anomalias positivas aparecem a partir do dia 22 sobre o centro-norte da Argentina, Paraguai e Rio Grande do Sul. Sobre o estado brasileiro a anomalia apresenta-se mais intensa entre os dias 24 e 27 com valores acima de $+6^{\circ} \mathrm{C}$, sendo superiores a $+9^{\circ} \mathrm{C}$ no oeste do estado. A partir do dia 28 , a anomalia diminui sobre o Rio Grande do Sul. abre-

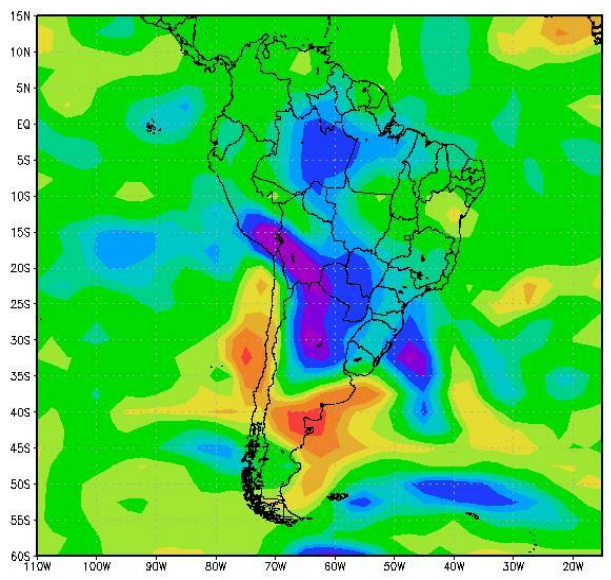

sentando-se fraca ao sul, com valores inferiores a $+4^{\circ} \mathrm{C}$, enquanto que no noroeste do estado ainda mantém-se significativa, com valores acima de $+6^{\circ} \mathrm{C}$.

O campo de vetor vento médio diário em $850 \mathrm{hPa}$ mostra que, entre os dias 21 e 29 (Figura 11 e 13 - mostrado apenas os dias 24, 26, 27 e 28), há a presença, em baixos níveis da atmosfera, de um fluxo de norte pelo centro da América do Sul, dirigido para o nordeste da Argentina, Uruguai e Rio Grande do Sul. A magnitude do fluxo mostra-se mais intensa entre os dias 23 e 26, quando supera os $15 \mathrm{~km} \cdot \mathrm{h}^{-1}$. O campo de anomalia do vento médio diário em $850 \mathrm{hPa}$ (Figura 12 - mostrado apenas os dias 24 e 26) revela a condição de anomalia de vento de noroeste entre os dia 22 e 27 sobre o Rio Grande do Sul. No dia 27 o vento gira para oeste e no dia 28 correntes de sudoeste alcançam o sul do estado (não apresentado), advectando ar mais frio para esta região, o que justifica a duração mais curta do evento nesta porcão do estado. Esta mudanca é também per-

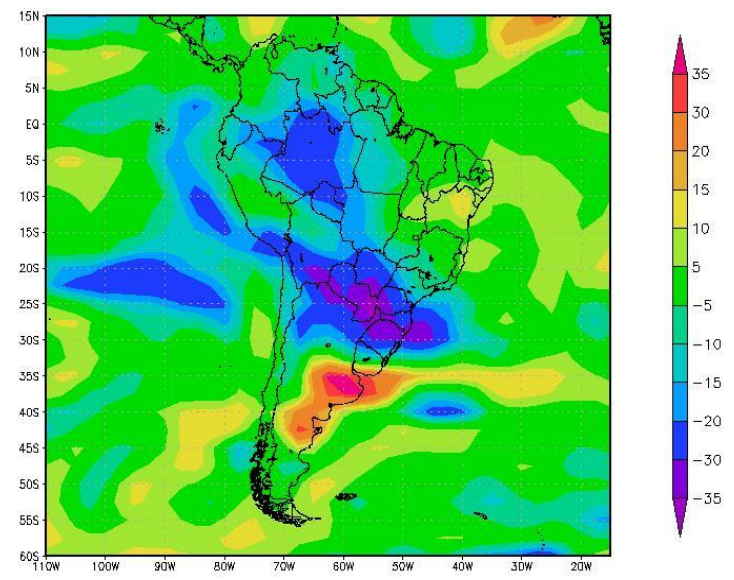

Figura 8 - Anomalia de umidade relativa média diária em 925hPa dos dias 24 e 26 de agosto de 1995.
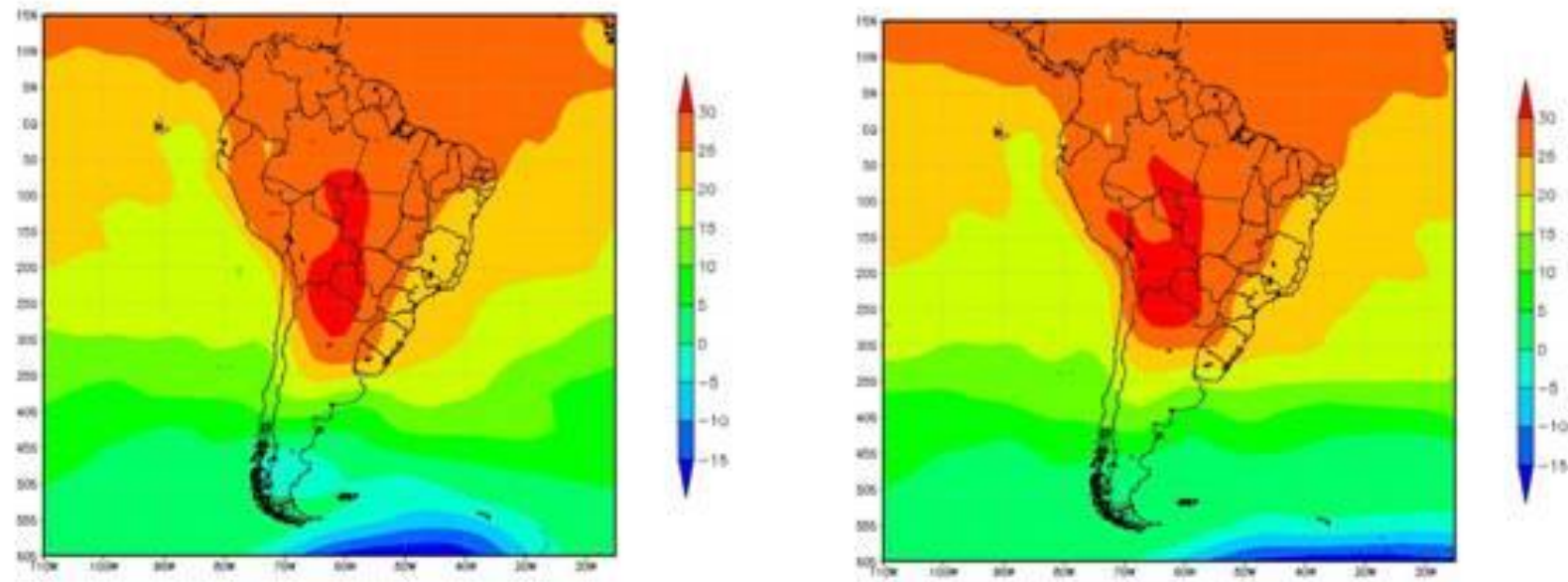

Figura 9 - Temperatura média diária em 1000hPa dos dias 24 e 26 de agosto de 1995. 

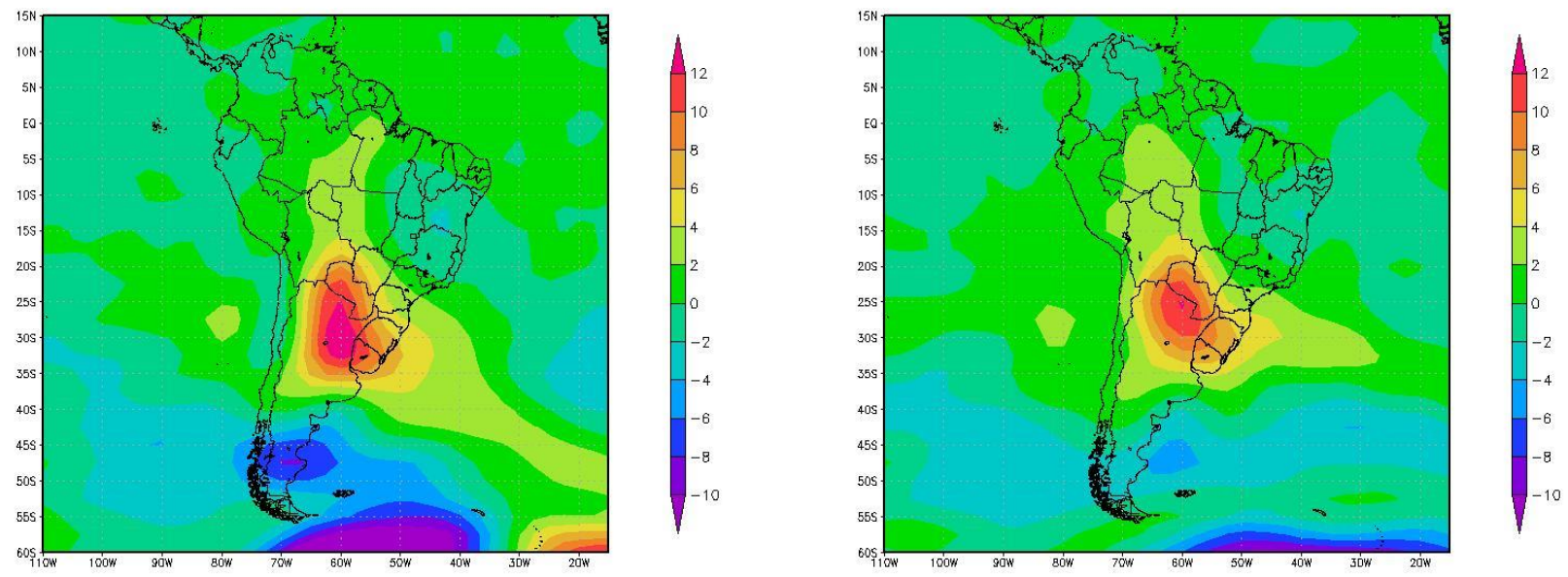

Figura 10 - Anomalia de temperatura média diária em 1000hPa dos dias 24 e 26 de agosto de 1995.
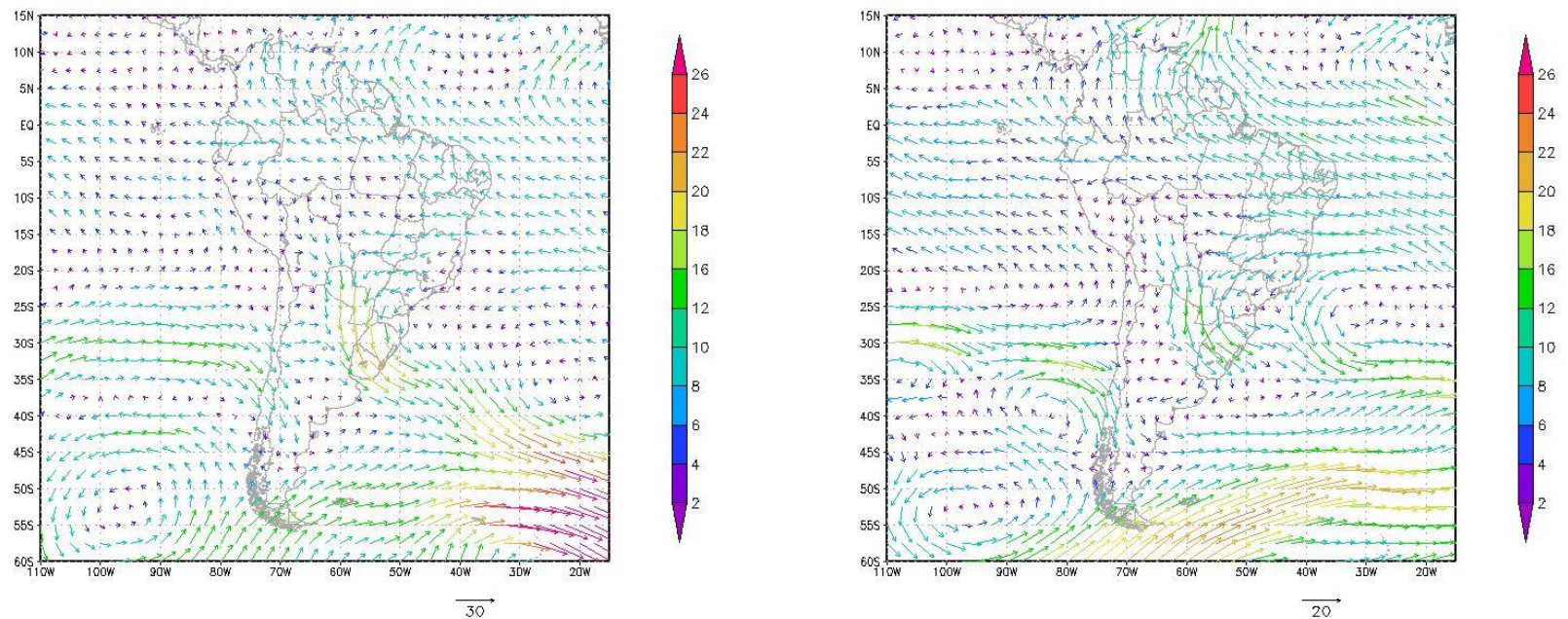

Figura 11 - Vetor vento médio diário em 850hPa dos dias 24 e 26 de agosto de 1995.
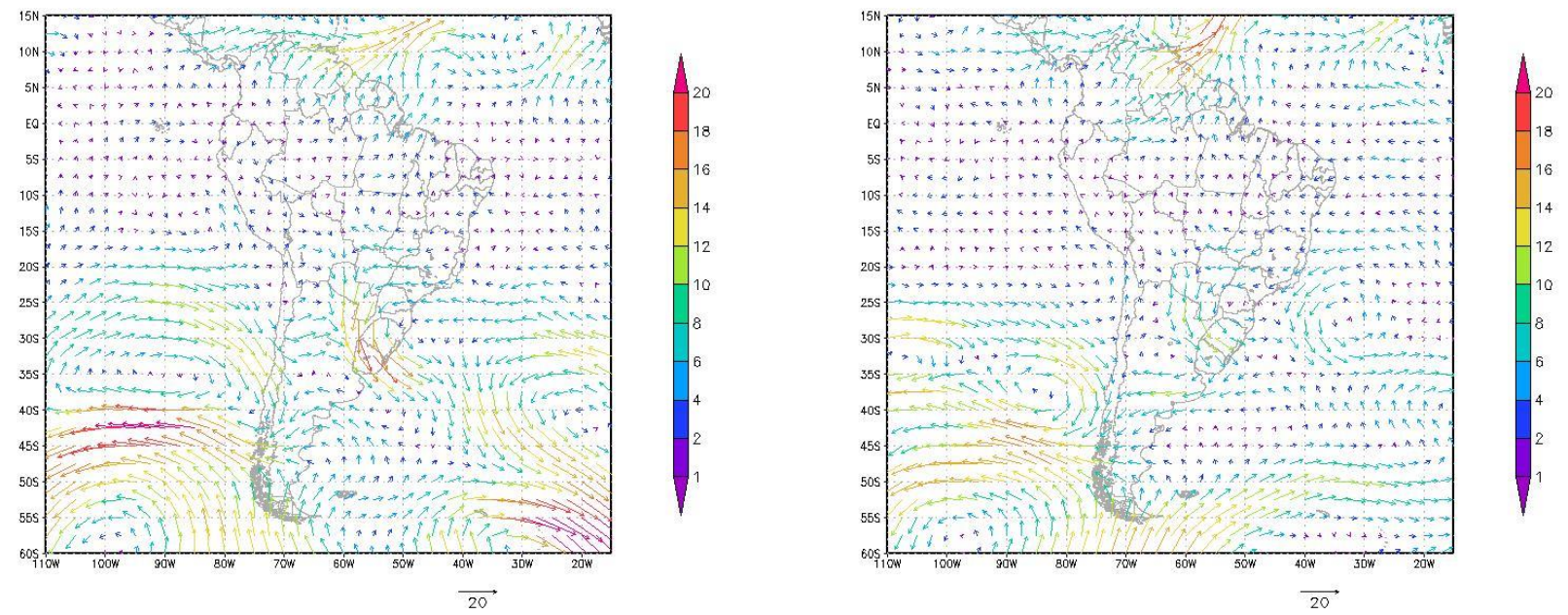

Figura 12 - Anomalia do vetor vento médio diário em 850hPa dos dias 24 e 26 de Agosto de 1995. 


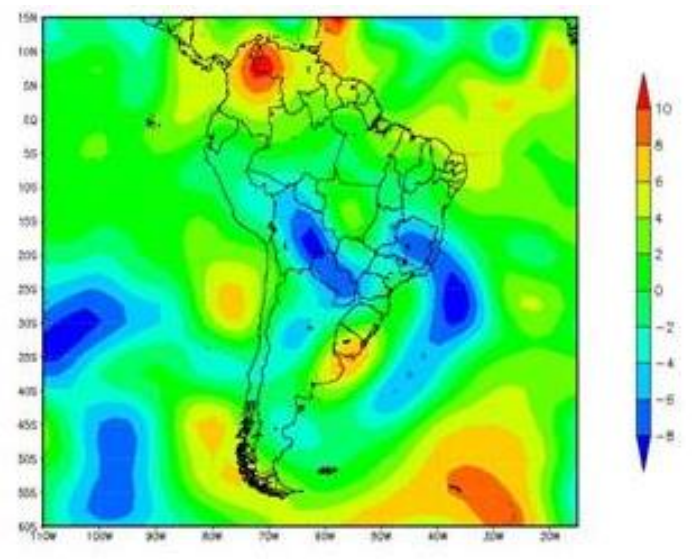

Figura 13 - Componente meridional do vetor vento em 850hPa do dia 28 de Agosto de 1995.

ceptível na análise da componente meridional do vento em 850hPa do dia 28 (Figura 13), que mostra claramente o sinal oposto da componente entre o norte (positiva) e o sul (negativa) do estado.

\section{Conclusões}

A incidência de veranicos nas cidades estudadas para o território do Rio Grande do Sul é marcadamente desigual, sendo significativamente influenciada pela proximidade do mar e por uma relação com a latitude. O fenômeno se apresenta relativamente comum ao inverno da região, uma vez que nas regiões afastadas do litoral a ocorrência foi em pelo menos metade dos anos de estudo. A incidência também é regular ao longo do período sazonal frio, mas não de todo homogênea, pois se apresenta muito maior em agosto.

Os resultados encontrados confirmam a eficácia da metodologia utilizada para identificação de veranicos com base em critérios climatológicos. A metodologia permite identificar o período típico de ocorrência de veranicos para um determinado clima, que no caso do Rio Grande do Sul é de maio a setembro.

Análise de um veranico ocorrido entre os dias 22 e 31 de agosto de 1995, que afetou algumas localidades até 09 dias, indicou que as configurações atmosféricas em níveis médios e superiores favoreceram a estagnação de uma massa de ar quente e seco sobre o centro da América do Sul, durante o período de evento. Esta situação impediu o avanço de sistemas frontais para o estado do Rio Grande do Sul, que advectariam ar frio após a sua passagem e fariam as temperaturas e umidade atmosférica oscilarem, bem como manteriam o regime de chuvas. Associado a esta condição, o campo de pressão à superfície dirigiu uma circulação de norte que advectou ar quente e mais seco para o nordeste da Argentina, Uruguai e Rio Grande do Sul, elevando, em grau anômalo para a estação, as temperaturas na região.
Entre os dias 27 e 28 de agosto, a passagem de um sistema frontal ao sul do Rio Grande do Sul afetou a porção sul do estado, interrompendo o veranico, porém não no norte onde o veranico persistiu até o dia 29 de agosto, quando a dinâmica da atmosfera passa a apresentar um quadro mais transiente.

\section{Agradecimentos}

Ao Instituto Nacional de Meteorologia pela disponibilização dos dados das estações meteorológicas em superfície e ao National Centers for Environmental Prediction pela disponibilização dos dados de reanálises.

\section{Referências}

ACOSTA, J. F.; CARVALHO, M. H.. Estudo de um caso de veranico observado em Pelotas-RS In: Congresso Brasileiro De Meteorologia, Edição XIII. Fortaleza, 2004.

ASSIS, S. V.; FERREIRA, A.T.; SILVA, M. V.. Veranicos em Pelotas, RS: Climatologia e causas da ocorrência. In: Congresso Brasileiro De Meteorologia, Edição XIV. Florianópolis. Florianópolis, 2006.

BRAUN, S.; SILVEIRA, V. P.; HERMANN, V. I.; NEVES, L. O.. Análise de casos de veranico em várias cidades do Rio Grande do Sul. In: Congresso Brasileiro de Meteorologia, Edição XI. Rio de Janeiro, 2000.

CONCEIÇÃO, L. F. C.; MARIANO, G. L.; H. CONRADO, H.. Análise da ocorrência de veranicos no Rio Grande do Sul. In: Simpósio Internacional de Climatologia, Edição V. Florianópolis, 2013. 
JACÓBSEN, L.O. Estudo de casos de Veranico em Porto Alegre/RS de 1961 a 1985. In: Congresso Brasileiro de Agrometeorologia, 11, 1999 Florianópolis, SC. Anais... Florianópolis: Sociedade Brasileira de Agrometeorologia, 1999. p. 1462-1466.

LUZ, L. A.; SCHILD, G. T.; MARIANO G. L.; CONRADO, H.. Metodologia de identificação de veranicos em Passo Fundo-Rs. In: Congresso Brasileiro De Meteorologia, Edição XVII. Gramado, 2012.

PRAKKI, S.; NOBRE, C. A.; SILVA DIAS, P. L. Tropics - South America. In: KAROLY, D. J.; VINCENT, D. G. (ed.). Meteorology of the Southern Hemisphere. Boston: American Meteorological Society, 1998. v. 27, p. 119-139. (INPE-11750-PRE/7109). 